\title{
Implications for Adoption
}

\author{
Joseph Lindley \\ Imagination \\ Lancaster University \\ j.lindley@lancaster.ac.uk
}

\author{
Paul Coulton \\ Imagination \\ Lancaster University \\ p.coulton@lancaster.ac.uk
}

\author{
Miriam Sturdee \\ HighWire CDT \\ Lancaster University \\ m.sturdee@lancaster.ac.uk
}

\begin{abstract}
In this paper we explore the motivations for, and practicalities of, incorporating 'implications for adoption' into HCI research practice. Implications for adoption are speculations which may be used in research projects to scrutinize and explore the implications and requirements associated with a technology's potential adoption in the future. There is a rich tradition within the HCI community of implementing, demonstrating, and testing new interactions or technologies by building prototypes. Usercentered design methods help us to develop prototypes to and move toward designs that are validated, efficient, and rewarding to use. However, these studies rarely shift their temporal focus to consider, in any significant detail, what it would mean for a technology to exist beyond its prototypical implementation, in other words how these prototypes might ultimately be adopted. Given the CHI community's increasing interest in technology-related human and social effects, the lack of attention paid to adoption represents a significant and relevant gap in current practices. It is this gap that the paper addresses and in doing so offers three contributions: (1) exploring and unpacking different notions of adoption from varying disciplinary perspectives; (2) discussing why considering adoption is relevant and useful, specifically in HCI research; (3) discussing methods for addressing this need, specifically design fiction, and understanding how utilizing these methods may provide researchers with means to better understand the myriad of nuanced, situated, and technologically-mediated relationships that innovative designs facilitate.
\end{abstract}

\section{Author Keywords}

Adoptability; Prototyping; Design Fiction; Implications for Adoption.

ACM Classification Keywords

I.m. Computing Methodologies: Miscellaneous.

\section{INTRODUCTION}

The motivation that led us to create this paper came from a very specific requirement: as part of a long-term research project it was necessary to develop a framework for working with the concept of 'adoption' in the context of technological research and development. As regular contributors to the $\mathrm{CHI}$ conference, and being well-aware of the huge breadth of perspectives on emerging technology in that community, we were immediately drawn to the corpus of HCI literature to begin our inquiry. Our initial literature search, specifically within SIGCHI conferences, yielded surprisingly few articles of relevance from the field. In one of the few articles we located that directly addresses adoption in a HCI context, a salient question was raised by Chilana et al. They ask whether doing "good science" will help us pass on what we discover in our research to users or consumers, or alternatively, is adoption beyond the scope of what we should be concerned with? "In short", they ask, "must we care?" [17].

Whilst Chilana et al. raise the question several times, they do not offer any concrete answers as to whether we (HCI researchers) should care about the potential future adoption of the interfaces and technologies we are researching. However, our argument is that we should care about adoption, an assertion naturally accompanied by questioning why should this be the case. By attempting to provide answers to these questions, we establish a motivation for researchers to consider potential future adoption of the technologies and prototypes they are working with. Once this motivation is established we describe how design fiction, among other methods, is well suited tool for incorporating 'implications for adoption' into research projects.

The paper is structured as follows, broadly fitting into three sections. First we review a range of literature from several disciplines in order to showcase the diversity of research relevant to the core idea being discussed (the potential adoption of emerging technology). The review's purpose is to explore a series of different logics for considering any technology's potential future adoption. In the second section, we focus on HCI literature in order to make the case as to why potential future adoption is of particular relevance and importance to HCI. At this point we will have established that speculating about adoption could be a useful endeavor, and also forwarded specific HCI-centric reasons for why this is the case. In the final section of the paper we describe and discuss strategies for how 
researchers may apply the ideas presented in this paper to their work, and discuss possible trajectories for further research in this area.

\section{YOU SAY POTATO, I SAY POTAHTO}

Disciplinary boundaries pervade academic endeavors, but HCI in particular sits at a disciplinary confluence $[8,62]$. Because of this positioning, different terms for similar phenomena or similar terms for differing phenomena, are commonplace. Therefore, it is useful to introduce and explore a few differing disciplinary perspectives and terminologies for concepts related to adoption of emerging technologies. It would be impossible to review each of these areas exhaustively and instead this section aims to make clear the breadth of existing perspectives on adoption and also introduce those perspectives which later on in the paper directly support the proposition that we conclude with; the incorporation of implications for adoption within research projects. Clarifying the diversity of perspectives serves two purposes. While it is important to simply acknowledge that these ways of looking at adoption exist, more significantly in terms of the paper's argumentation it is important that we demonstrate the gap in existing practices. By making the nature of this gap clear, the proposal to include implications for adoption in $\mathrm{HCI}$ research projects, is explicated with as much context and clarity as is possible. The first area we review concerns moving technology research out of academic environments and towards commercialization.

The practice of developing not-for-profit research so that it can be commercially exploited is an area of interest and study that was formerly referred to as 'technology transfer' but in modern terms is usually referred to as 'technology exchange'. This could involve a research organization imparting to a commercial organization a prototype to be refined and marketed, an idea that can be developed into a new product, an idea that can improve an existing product, an idea to help mitigate failure for an in-progress project, or practices that make operations more efficient [32]. The defining factor in such activities is the bipartite relationship: there is always a research entity and a commercial entity that are required to work together [36]. The change in terminology, from transfer to exchange, reflects the realization that the relationship between the two entities is rarely one direction or linear, and requires knowledge to flow back and forth between partners, and envisioning it as a simple one-way flow can be harmful. Chilana et al pose a series of intriguing questions in their CHI paper that studies the transfer of technology from a University research project into a startup company. With awareness that $\mathrm{HCI}$ research is usually assessed in terms of feasibility, novelty, and generalizability, and noting that "many researchers believe in making research contributions for the sake of advancing knowledge alone", they ponder "Even if commercialization is not the eventual goal, a focus on adoption might still be helpful for reflecting on design choices and research questions" [17]. One intention of this paper is to reconcile these two perspectives (the first being that research is done for the sake of knowledge alone, the second being that considering adoption may help reflect on design and research questions) and in doing so pose a rhetorical argument that exploring the potential adoption of an emerging technology, may, in itself, contribute to the advancement of knowledge and help to refine design and research questions. While studies of efficient technology exchange may offer some insights that are eventually applicable to adoption, for the most part the research in this area is about relationships between people. Foley points out "People, not papers, transfer technology" and that "fully understanding the product development cycle, academicians, will gain a more realistic view of their roles in the process" [32]. Both sentiments are indicative of how technology exchange does not, in isolation, explore or research how a particular technology may be adopted, or what the implications of its adoption may be. Rather studies in this area explore how to cushion the blows of this "contact sport" [32], or how to manage the exchange process. There is an implicit assumption that if the exchange is done well, then adoption 'should happen', but little effort to explore what that adoption's impact might be.

Another school of thought when considering adoption, prevalent in studies of Management Science and Information Systems, is the Technology Acceptance Model (TAM). TAM extends the Theory of Reasoned Action, an idea grounded in social psychology [31], which quantifies and balances various factors related to potential users of a system (e.g. their beliefs, attitudes, and intentions). Although primarily studied and applied in workplace settings, and hence its 'home' disciplines being management-centric, TAM frequently extends sideward into marketing studies [46]. Aiming to understand how the factors integral to the Theory of Reasoned Action interact vis-à-vis technologies in the workplace, TAM looks at the relationship between perceived usefulness, ease of use, and how these may impact potential future usage of a yet-to-beimplemented technology system. TAM attempts to provide managers with an opportunity to intervene and improve a system before it is implemented, thus avoiding the costly pitfalls of developing or implementing a system that either is not useful, or will not be accepted by users [23].

Although widely used, TAM is not without shortcomings. For example recent research suggests that constant reformulation of the model, which is necessary to keep pace with technological progress, has left TAM, and its many decedents, in a state confusion [6]. The original research proposing the model has significant empirical support, which has been successfully replicated, however neither the original model nor the replications successfully take account of a number of phenomena that are very likely relevant to conclusions based on the model: "It may be that a variety of factors, such as user experience, type or sophistication of system use, or other task and user characteristics may mediate the relationship between ease 
of use and usage" [1]. Hence, while it is accepted as a useful tool, and bootstrapped by strong empirical foundation, TAM is not a definitive approach for understanding a system's potential for acceptance. As Segars and Grover point out with regards to ease of use and usefulness, central to any prediction based on TAM, "no absolute measures for these constructs exist across varying technological and organizational contexts", going on to hint at why this may be the case they add "it seems plausible that both task and user characteristics alter the nature and important perceptions that explain technology use" [68]. Legris et al also note that empirically TAM can be shown to be effective in certain contexts, but that most of the data that form the empirical base for the model come from artificially sterile environments, for example based largely on students, self-reported data, and a narrow scope of contexts and technology types [44]. When the true complexities socio-technical relationships are taken into account TAM's ability to present meaningful views into the future is drastically reduced. TAM's focus is on whether a system can be used, and sidelines the potential implications for its use. Hence while it is relevant to our inquiry into adoption, it seems that TAM-derived answers are constrained to a relatively tightly scoped set of questions.

The anthropologist Lucy Suchman's concept of 'situated action' describes a complex and mutually interdependent assemblage of action, context, social and technological factors [75]. It is this type of complexity that approaches such as TAM struggle to meaningfully account for, hence we turn to the social sciences for more nuanced perspectives on these factors. The diverse variety among the sites of inquiry that social scientists draw upon is in stark contrast to the relatively concise domains of inquiry that studies of technology exchange and TAM frequent. Technology exchange is limited to commercializing research-backed technologies - which naturally limits which technologies (i.e. those that have a potential market) and which organizations studies of transfer are relevant to. Meanwhile TAM tries to ensure new systems will be seamlessly incorporated into businesses (usually large corporations) at minimal cost and without resistance from the workers. In contrast, social studies of technology observe a vast range of different users, environments and technologies and these are used to form theories that are relevant to a multitude of complex questions (e.g. how innovations are anticipated, transferred, accepted, adopted, and domesticated) [57]. In the following we offer an overview of some of these ideas and approaches from the social sciences that are relevant to the notion of adoption.

The social construction of technology (SCOT) was the first step toward superseding an outdated view that cast users as inert entities in their relationship with technology. Moving beyond the view that users are simply consumers of technology, Pinch and Bijker explore the notion of 'interpretive flexibility' in order to develop their perspective on SCOT. Interpretive flexibility can be reduced to the idea that an emerging technology can be interpreted differently by different social groups. A famous example is the pneumatic bicycle tire, a cutting edge technology of the 1890s. Before the technology was adopted, engineers developed their own perspectives on what pneumatic tires could be for: as a means to reduce vibration, as a way to increase speed, to increase comfort, while skeptics suggested that they were dangerous, prone to deflation, and ugly [61]. The bicycle study is just one of many such examples, usually looking back at technologies that have been adopted. They tend to point to patterns of changes as more people are exposed to, and begin to use, new technologies. Firsthand practical knowledge amasses, consensus emerges, and diversity of opinion about the technology's possible applications and meanings, reduces. In other words, adoption causes the interpretive flexibility to decrease, and as a result a socially constructed understanding of the technology stabilizes. An interesting facet of this process is that often the stabilized 'meaning' of the technology as it has been socially constructed is quite different to the original purpose [60]. Although early SCOT studies focused on how early adopters shaped the meaning of the technologies, later studies showed that in some circumstances users are able to reconstruct apparently stable technologies too [40].

In addition to SCOT there are a whole host of other sociologies which may be used to shed light on the adoption of technology. While the multitude of differing perspectives can be useful, they also highlight the lack of any cohesive or unifying theory. Woolgar describes users as 'readers' (inferring that technologies may be considered as text) and uses this as a means to understand any given device or machine's interpretive flexibility [80:60]. He describes how machines 'configure' their users with meaning that is 'encoded' within the designs. For some scholars this formulation appears one-dimensional and neglects the 'decoding' process: any reader of a novel, after all, has the agency to interpret the text on the page [51]. Hence we can say that while designers encode meaning which configures users, users themselves have the potential to influence designers (this is somewhat similar to Buchanan's argument about design itself being rhetoric [14]), designers, then, reencode new meanings into their designs, which of course are intended to be adopted by users and hence the cycle repeats. Akrich employs a similar metaphor, this time describing a given technology's relationship with potential users it in the same terms that an actor relates to a film script [2]. Just as actors interpret a script they are performing, users of a technology interpret the technology. While both film actors and technology users are unavoidably influenced by what the script writer put on the page (or the designer designed), they also have the ability to enact the script (or the technology) in their style. "We have to go back and forth continually between the designer and the user, between the designer's envisioned users and the real users, between the world inscribed in the object and the 
world described by its displacement" [2]. Acknowledging this cyclical and reciprocal relationship between entities in technology adoption is echoed by domestication theory too. Domestication theory, which although called a theory is primarily an analytical model, describes how technologies are integrated into everyday life, users and contexts adapt to the new condition (as modified by the technology), these adaptations are then folded back into the innovation cycle. Rooted in studies of technology in household settings, the theory has since been applied outside the home too, but introduces its own terminology and style [70]. Actor network theory, media and cultural studies, feminist perspectives - to name a few - offer their own nuanced accounts of how technology and people collide, and how those collisions sometimes result in widespread adoption of the technologies [57]. Although all of these delicately different perspectives are fascinating, and for the conscientious scholar can provide valuable insight, an in depth study of them is not viable in the context of this paper. Nor is such an in depth exploration of them necessary to galvanize the core of our argument. For the most part, an awareness of SCOT, interpretive flexibility, the co-evolution of meaning as a product of environment, technology, design and users, will suffice.

With that said, we want to acknowledge there are a number of other related concepts we have not discussed in detail, including anticipation ('the sociology of expectations' $[3,13]$ ), foresight $[64,65]$ (generating and interpreting future policy ideas, for example), and scenario planning $[58,67]$ (constructing shared narratives about possible futures). There have also been interesting attempts to unify psychological approaches such as TAM with other theories of acceptance and methods such as user-centered design [24]. Although each area of study has its own properties, as with the differences between sociological perspectives, for the purposes of our argument we can assume that they are variations on those we have already introduced. To briefly recap, technology exchange explores the dynamics of how research, done purely for the sake of knowledge, may be transferred to a commercial setting. TAM provides managers with tools to reduce the risk of a yet-to-beimplemented technology system being difficult to use and therefore being rejected by users. The range of sociological lenses describe, for example, how technologies are shaped by users, that designs contain encoded meanings, and that technologies are usually adapted and interpreted in order for interpretive flexibility to stabilize and the technology to become domesticated.

While all the areas reviewed have individual focal points, a single concept that unites all of these endeavors is an attempt to understand the what a particular technology's adoption means (albeit with different perspectives on how meaning may manifest itself or be relevant). If we return to the question 'should we care about the potential future adoption of the interfaces and technologies that we are researching?' then we might extrapolate that each of these modes of inquiry indicate reasons why the answer could, in circumstances, be yes. Perhaps, 'yes, because the prototype may be commercialized later'. Maybe 'yes, because we want to ensure that the system will be accepted by users'. Or, 'yes, because if people do use this system, it could impact upon them, their lives, society in general, and perhaps future technologies too'. Finally, we may consider 'yes, so as to align with research impact agendas' (a factor that is increasingly relevant). If any of these factors are of relevance to HCI research, which is likely the case, then it should be clear that adoption is a material concern.

Before we discuss HCI-specific literature and elaborate on why we consider adoption to be particularly relevant to our field, we wish to refer to Gartner's famous 'hype cycle' concept and diagram. We were somewhat reticent to refer to the diagram because despite its familiarity to researchers and commercial innovators alike, there is scant empirical support for its applicability in any given domain or context $[37,45]$. Despite such potential for criticism we note the compelling nature of the diagrams rhetoric in technology research and development and thus elected to include it. For the purposes of the paper the diagram should be taken as a figurative aid for conceptualizing where the various concepts discussed sit in relation to each other.

The hype cycle places technologies on a graph of time (xaxis) against expectations and/or exposure (y-axis). Starting with a technology trigger exposure and expectations grow quickly to a 'peak of inflated expectations'.

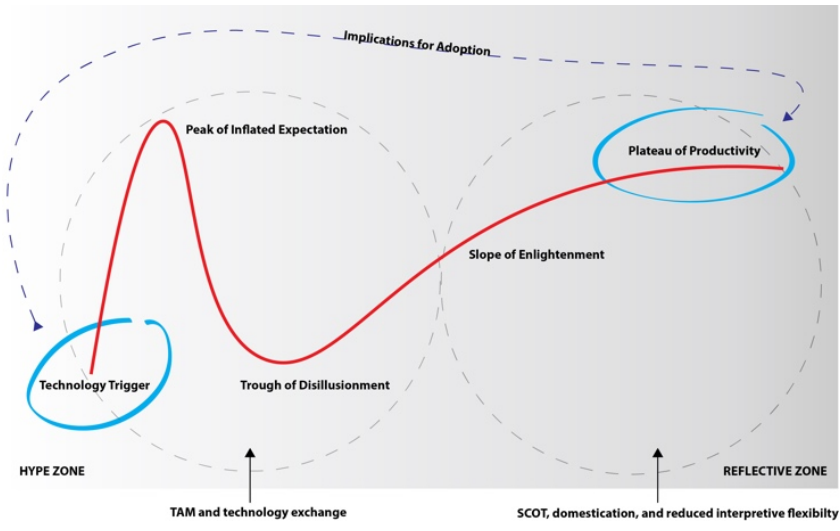

Figure 1. Adapted version of hype cycle illustrating where different approaches may be relevant, and the gap that 'implications for adoption' intends to bridge.

This initial hype, quickly, falls away leading into a 'trough of disillusionment'. Exposure and expectations then grow again, this time more slowly, up the so-called 'slope of enlightenment'. Finally, the technology stabilizes at the 'plateau of productivity'. These phrases provide a temporal spectrum upon which the various ideas and concepts discussed in this paper can now be mapped. For instance, drawing upon ideas introduced thus far, an invocation of TAM would almost definitely take place somewhere on the left-hand side of the diagram (which we have labelled the 'hype zone'). TAM is employed here in an attempt to make 
the route to the right-hand side of the diagram (which we have labelled the 'reflective zone') as flat as possible, avoiding peaks and troughs. TAM and similar approaches, act on the left, in order to tame the right. Conversely, if we think about SCOT, interpretive flexibility, domestication, and the other sociological perspectives discussed, the studies that inform these views may take place at any point on the diagram, but the point at which technologies stabilize, have reduced interpretive flexibility, and may be considered 'domesticated', invariably sits them on the plateau of productivity. At various junctures in the subsequent sections of the paper, our augmented version of the hype cycle is referred to. It is not intended to be reductive, but rather an efficient vehicle for metaphorically unifying the disparate components parts of our argument.

In the following, we focus on HCI-specific literature, discussing ideas including proximate futures, HCI as 'interdiscipline', and the role of user-centered design methods. Together these factors develop a robust argument for why HCI researchers should carefully consider adoption as part of their research endeavors.

\section{HOW WE LEARNED TO STOP WORRYING ABOUT SCIENCE AND LOVE THE PROXIMATE FUTURE}

The "proximate future" referred to in the section header is that described by Bell \& Dourish, who used the phrase to articulate how 25 years of Ubiquitous Comptuing (ubicomp) research has invariably framed the technologies and concepts being researched as 'out of reach' or 'just around the corner' [5]. This rhetoric was inherited from ubicomp's foundational texts, largely attributed to Mark Weiser [78], yet over the intervening 25 years the same sentiments persist, despite much of what was contained in Weiser's original vision having already been achieved. One critique of ubicomp's tendency towards the temporal extrapolation that Bell \& Dourish draw attention to, is that future framing in this way appears to encourage researchers to shirk responsibility for actually implementing the technologies that they help to develop. In ubicomp texts, implementation is effectively externalized as "someone else's problem", inferring that innovation and research should exist in its own walled garden, completely away from the 'messiness' that a vision which accepts the social construction of technological adoption in everyday life would necessitate. Arguably, in doing so, this trope of ubicomp research texts devalues the research itself, by unnecessarily segregating the knowledge production endeavor from a lived reality [5]. Another way to consider, what we argue is the inherently proximately futuristic quality of HCI, can be found by peering into HCI's alleged 'big hole'.

The so-called big hole was exposed by Liu et al through a bibliometric analysis of 20 years of CHI publications [50]. Their findings conclude, based a co-word analysis [16], that researchers contributing to $\mathrm{CHI}$ pursue relatively shortlived and diverse technical trends as opposed to focusing on a small number of core themes and studying them over a longer period of time (what the authors call 'motor themes'). One of the authors, Kostakos, reflects critically on the analysis and makes the observation that in the HCI field, researchers do "not systematically get behind a small number of topics to advance them sufficiently into the mainstream" and that we "simply roll from topic to topic, year after year, without developing any of them substantially" [41]. If we refer back to the hype cycle and try and place this type of HCI research on it, the "bandwagon" themes that Liu et al and Kostakos are referring to align very much with what we termed the "hype zone'. According to the co-word analysis very few HCI research programs stick with a theme until the associated technology has been domesticated, instead they jump from emerging technology to emerging technology without considering the products of their research on a continued journey towards the 'plateau of productivity'. Kostakos describes this as a "very worrying prospect for a scientific community" [41], but that sentiment can also be cast in a less negative light. In the subsequent paragraphs we take an alternate view on what kind of discipline HCI actually is, consider how that disciplinary status relates to HCI's 'motor', and ask what the motor's relationship to the proximate future is.

Blackwell suggests that if we consider HCI an 'interdiscipline' then the tendency to not settle on motor themes is actually a definitional feature [8]. In Blackwell's view the lack of a 'stable core' in HCI is not a concern at all, but rather is an inevitability for a field that pulls influences from, and contributes to, an array of other disciplines. He states that, as opposed to other more traditional areas of academic inquiry, HCI's purpose should not be to maintain a steady mass of knowledge, but to act as a catalyst for innovation. The use of the adjective 'motor' to describe the themes that Liu et al identified as missing in HCI, is no accident, but the 'motor' is of course metaphorical. As with an automobile, the motor is what provides power and drive to move things forward. Blackwell argues that the metaphorical motor of HCI is in fact present. He says the lack of stable long term themes, which in other disciplines (e.g. medicine or psychology) and motor, is not relevant to HCI in the same way. Hence, we would expect Liu et al's search for these 'motor themes' to be fruitless (and perhaps the search was misplaced in the first place). Reeves' reflection on the 'big hole' dissects the same argument eloquently, surmising that in order to posit the big hole's existence, some bold assumptions are frequently made about HCI's disciplinarity; the very concept of HCI as a 'discipline' is problematic in the first place; and these problems are deepened by considering HCI a scientific discipline [62]. Reeves' perspective seems in agreement with Blackwell's.

If we consider HCI an inter-discipline, the 'motor' of $\mathrm{HCI}$ is the desire to innovate and to forge new ground. In particular forging new ground in the space between various 
facets of innovation including technical, engineering, human, and social aspects. From this perspective, then, arguably the 'proximate future' is actually a key component in what defines HCI. While ubicomp always intended to look at what was lurking over the horizon of the near future, for HCI-as-inter-discipline it is an implicit and definitional feature. By following these new trends HCI acts as a catalyst and driver of innovation. Returning to our adapted hype cycle, we can place the work of many HCI researchers on the left hand side of the diagram, researching and working with technologies that are very new and have limited exposure. Whether you subscribe to Kostakos' assertion that researchers 'roll from topic to topic, year after year', or if you prefer to see this positioning in terms of Blackwell's inter-discipline innovation motor, or if you see a consonance between Bell \& Dourish's observations of ubicomp and HCI's futurity, all of these views place much of the work emerging from our field towards the left hand side of our adapted hype cycle.

If this proximate quality is central to the endeavor of $\mathrm{HCI}$ research, as it seems to be, then we suggest heeding Bell \& Dourish's warnings about these perpetually-arriving proximate futures is actually crucial. Rather than using the inevitable messiness that occurs when the technologies we research interact with the realities of everyday life as an excuse to avoid thinking about adoption, we should use it as a strong motivator for considering adoption. Unifying concerns about the proximate future, worries about HCI researchers' tendency to jump to the 'next big thing', and connecting them with the notion of HCI as inter-discipline, is the overarching theme cementing together this paper's premis. Describing this in terms of our modified hype cycle, the purpose of this paper's thesis is to provide researchers with an efficacious means to bridge the gap between hype zone and reflective zone by leveraging 'implications for adoption'. Although its foundation is now established, in the following paragraphs we introduce a series of resonant perspectives to buttress and brace our argument with addition HCI-centric perspectives.

In their paper introducing the notion of 'research products' Odom et al observe that "a growing portion of the HCI community has moved beyond designing for efficient use to investigating complex matters of human-technology relations that often involve messy, intimate, and contested aspects of everyday life". This sentiment immediately resonates with our modified hype cycle, 'designing for efficiency' which they refer to has synergy with usability studies that take place while technologies are in the hype zone, meanwhile the 'complex matters of humantechnology relations' emerge with respect to technologies which have taken some steps towards domestication. Their argument continues: when adopting an artifact-based design response to the 'messy, intimate, and contested' questions that the HCI community is increasingly interested in considering, it is useful to frame the interactions people have with research artifacts "predicated on what it is as opposed to what it might become" [56]. By this they mean that research products are presented as 'finished' articles, as opposed to being defined by the inherent contingency imported by referring to the research artifacts as 'prototypes'. Research products, though, are not defined solely by reframing the artifact as 'final'. Another definitive factor is that they are installed in 'real' environments (such as research participants' homes) as opposed to being confined to laboratory contexts. Despite this, the properties of what delineates a research product from a research prototype are very subtle, and could likely be disputed. However, for the purposes of this paper, these definitional nuances of research products are inconsequential. Rather, our motivation to refer to this work lies in the reasons why research products seem useful: because they look beyond usability studies of prototypical implementations and work towards simulating situated proximate futures (incidentally projects falling under the banner 'research in the wild' have similar motivations and methods [20]). As the authors point out the motivation for moving towards understanding situated phenomena stems from HCI's increasing interest in the intricate, entangled, and intimate messiness of individual and societal relationships with technology. If we relate this to our core argument, then the proximate futures which are so common in HCI research are increasingly about people and technology together, about how people use technology, and about how technology is adapted by people. Research products attempt to provide a means for researchers to shift their focus from the hype zone, and into the reflective zone, where technologies are beginning to become domesticated.

Arriving at findings that resonate with the motivation behind research products, Greenberg \& Buxton critique how empirical usability evaluations became a status quo in HCI research. They emphatically make the case that usercentered design (UCD) techniques, specifically usability evaluations, have major and significant role to play for HCI. Their full position is more critical though, they argue that we should be aware that non-empirical methods alongside empirical ones may help to deliver findings that are more representative of reality, depending on circumstance. While the assert that usability testing is often the best method available to understand a new system or interface, they qualify this saying that it applies 'in many cases, but not all cases'. They suggest that combining a variety of methods "will likely help triangulate and enrich the discussion of a systems validity". The bottom line in their critique of usability evaluations is that they "may incorrectly suggest a design's scientific worthiness rather than offer a meaningful critique of how it would be adopted and used in everyday practice". Finally, as well as misrepresenting the complexity of how technologies become situated outside of research and development contexts, it is also noted that usability studies can actually stifle innovation by 'muting' concepts that do not conform to established norms and 'quashing' radical new designs 
that rely on immature technologies [34]. In his article on 'activity centered design' Don Norman, perhaps one of the most famous proponents of UCD, comes to similar conclusions, suggesting that while UCD can help develop good products it can also make "improvements to bad ones" [54]. Elaborating on the same idea, Norman and Verganti discuss how "meaning change" can be a key driver to take more radical designs out of the hands of early adopters, and into the mainstream [55]. Mapping these thoughts to our adapted hype cycle, we suggest that UCD, and incremental design improvements may help a specific technology to flourish within the realm of the hype zone, however to branch out and beyond, 'meaning change' can be engendered by considering implications for adoption.

Greenberg \& Buxton, Norman, and Odom et al are all observing the unavoidable mess of 'doing stuff in the world'. When technologies encounter people, and people interact with the technologies in real environments, then a Pandora's box of possibility is opened. Strategies for how to contain and harness the contents of that box are not straightforward to locate, and less so to utilize. Norman's notes on activity centered design include the observation that people adapt to technology just as much as technology adapts to people, if this is the case, how do we account for it in our designs? He points out that UCD does not have all of the answers. Odom et al respond to the quagmire of complexity by crafting artifacts, and placing those artifacts into the world, usually around people. Through close observation of both the design process and the domestication process that the artifacts and people go through, they discern deeper insights about the interplay between technology and users. Greenberg \& Buxton's contribution is framed as a warning against blindly assuming a usability evaluation is the right thing to do in all circumstances, but also includes a number of practical steps to avoid the pitfalls they identified. They suggest paying attention to 'getting the right design before getting the design right' by sufficient use of what they call 'sketching'. They also advocate for using a range of design-led research methods alongside empirical methods [34].

For these perspectives to make sense in the broader scheme of the CHI community while we must allow our field to covet and pursue "appropriate rigour" we should not get hung up on what is or is not "scientific" [63]. What is more, the rigor our community is able to deliver, as per Liu et al's analysis and Kostakos' subsequent critique, almost certainly does not sit within the 'big hole' that they called 'quadrant 1' (stable, mainstream, motor themes) [41,50]. Instead the rigor that we can collectively draw upon, and that strengthens HCI's kernel, requires the use of appropriate methods for appropriate tasks [34], must appreciate that our field is a catalyst for innovation, is only defined by its relationships to other fields [8,62], and that $\mathrm{HCI}$, for better or worse, has an intrinsic relationship with the proximate future [5]. Concluding his response to Liu et al, Blackwell says "HCI is not about static knowledge, but ways of deploying and engaging with knowledge in a technological setting" [8]. Our thesis is about strengthening HCI's design discourse by demonstrating why and how to explore the potential future adoption of the emerging technologies that are the subject of HCI research. In our concluding section we describe our proposal for formalizing one way in which design fiction can be applied in HCI research in order to generate implications for adoption'.

\section{IMPLEMENTING IMPLICATIONS FOR ADOPTION}

The title of our paper makes reference to 'Implications for Design', a trope in HCI research papers which makes particularly regular appearances in research based upon ethnographic fieldwork. In short, implications for design sections try to surmise the findings of field studies into easy-to-interpret, and perhaps generalizable, findings that other researchers (and/or designers) can utilize and build upon. How researchers, interpretations of ethnographic methods, and review processes, inform the inclusion, production, and relevance of implications for design continues to be a contested space $[21,25,41,66]$ - and is not an area that this paper intends to encroach upon in any significant way. However, there is commonality between our proposal and discussions related to implications for design. The common ground, and why we saw fit to title this work 'implications for adoption', is that implications for design sections attempt to package insights, which are invariably complex and nuanced (or based upon work that is), into a relatively palatable and succinct delivery mechanism. Consonantly, our call is for packaging speculations about the potential future adoption of a currently emerging technology into a relatively digestible and concise delivery mechanism. Perhaps emphasizing this common ground further, the ethnographically informed studies which often result in implications for design are imbued with a 'situated' [21,75] quality that, as will be discussed below, we believe implications for adoption should be too (insofar as speculations ever can be situated).

In the following paragraphs, we discuss how researchers might create and incorporate implications for adoption into HCI research, however our proposals are intended to be suggestive rather than prescriptive in order to avoid the pitfalls of what Dourish referred to as "genre conventions" [25]. Although we are at pains to make it clear our position is not reductive or dogmatic - i.e. there are undoubtedly other ways to appreciate implications for adoption because it appears to be exceptionally well aligned with our conception of implication for adoption, we pay special attention to design fiction.

\section{Aligning with Design Fiction}

The concept of design fiction, originally a term coined by the writer Bruce Sterling [73] but significantly further developed by designer and researcher Julian Bleecker [9], is a method of speculative design which focuses on building fictional worlds [in press]. Design fictions contain users, 
environments, and technologies. The technologies they contain may often be 'real' insofar as they exist in some early or prototypical form in the present, however they are 'fictional' in the way they are diegetically [cf. 35] presented in a fabricated future. Although the HCI corpus includes magical [22,30], ironic [11] and humorous [15,39] design fictions, frequently they are built around speculations which attempt to trace plausible trajectories [4]. Among this class of plausible design fiction, building fictional worlds using familiar media and using those media to describe mundane use cases in everyday situations [48], has historically demonstrated design fiction's propensity for effectively suspending disbelief [19]. By suspending disbelief in this way design fiction opens a potential to deeply consider the potential implications of an emerging technology.

Our proposal is to utilize design fiction for implementing implications for adoption, however that suggestion should not be taken without acknowledging a broader discussion which includes caveats and appreciates alternatives. For example, we note that design fiction has been applied broadly in HCI for many other purposes, including to generate ideas [52], prototype interactions [35,74], question solutionist tendencies $[12,30,42]$, scrutinize research agendas $[39,49]$, and to encapsulate or communicate research findings $[12,43]$. As diverse as the purposes for which they are created, design fictions are not media specific, and have appropriated a variety media and presentation formats, for example video [53,79], text $[10,15,30]$, and illustration $[43,74]$. Design fictions worlds, therefore, can be built using virtually any media artifact or combinations thereof. It is important to remember that these two diversity attributes of design fiction mean although we do feel design fiction may be employed as a useful tool for exploring implications for adoption, given the diversity of practice, of course not all design fictions will necessarily be so well matched. Put differently, just because some humancomputer interfaces are good for inputting text, does not mean that all interfaces good for inputting text..

It is also worth noting that across the huge gamut of techniques employed by HCI researchers (particularly design led approaches to reflexivity and futures) there are numerous similar-but-related practices which collectively include some of the same attributes as design fiction. These include approaches such as scenarios [81], research products [56], conceptual design proposals [33], critical design [27], counter-functional design [59], reflective design [69] and propositional objects [77]. Whilst these approaches have merits when considering how to implement implications for adoption, design fiction is, in fact, uniquely positioned. Design fiction can leverage world building to create plausible, mundane, and speculative futures, within which today's emerging technologies may be prototyped as if they are domesticated and situated - two properties with direct relevance to implications for adoption. However, for clarity, we must stress that as with all design fiction, the speculations are not intended to be predictions or premonitions. Rather, provocations to serve as lenses to focus the plurality of multiple possible futures that are before us, such that they can be better critiqued from the present [cf. ,18,28].

This general discussion about design fiction is intended to demonstrate how elements of the practice are naturally aligned to the needs of implications for adoption. Specifically, design fictions depict emerging or nascent technological concepts [e.g. 26,41,45,70]. Design fiction allows these concepts to be prototyped as if they have become domesticated. Resonant with HCI's increasing refocusing on human-technology relationships, design fictions represent situated assemblages of environments, users and technologies. These factors demonstrate how design fiction can be an effective bridge from the left-hand side of our adapted hype cycle to the right-hand side. Using design fiction, 'technology triggers' can be explored as if they are already on the 'plateau of productivity' and this can be done in such a way that the technological sensibilities of sociological lenses for understanding future technology (such as SCOT) can be meaningfully represented. While it is beyond the scope of this paper to include an original demonstration, in the following we refer to examples of design fiction which include speculations congruent with our characterization thus far.

In PeriodShare Søndergaard and Hansen created a design fiction world utilizing several elements (physical prototype, crowd funding campaign, a petition for future users, and a performative intervention) that explores a future where wearable technologies facilitate the collection, sharing, and monetization of data pertaining to menstruation. The technology required to facilitate sharing and monetization of menstruation data is contemporarily available (indeed several apps already collect this kind of data, although the presence or lack of a monetization aspect is unclear). The use of design fiction creates a broader and self-consistent world within which menstruation, through its monetization, is more desirable (by implication, 'than it is today') and acts as a vehicle to explore the domestication of that technology. Unfortunately, as the authors acknowledge, "PeriodShare opens up a space for discussions that are deeper and wider than initially explored in this note" [71]. Perhaps as a limitation of publishing conventions that their note was restricted to, Søndergaard and Hansen's work does not, in isolation, complete the leap from the left to the right-hand side of the hype diagram. Communicating the depth of a given design fiction's world, within the confines of a research paper (or even a section of a research paper) is likely a substantive challenge in using design fiction to implement implications for adoption.

In making the case for creating design fictions as 'fictional papers' [48] Lindley and Coulton's refer to Game of Drones [47]. Game of Drones explores the practicalities of a drone-based civic enforcement system. As well as touching upon the usability of such as a system, the authors 
claim it also intends to provoke considerations related to "wider societal and ethical issues of technological futures in which drones might be widely adopted" [47]. Their use of the word 'adopted' suggests that their intention was to explore the 'implications for adoption' of the technology concept in question. By inventing the details of a user trial to study how drone-enabled civic enforcement could work, Lindley and Coulton's design fiction goes further towards concretely stimulating implications for adoption than, for instance, PeriodShare. With that said, it seems implausible to suggest that researchers should be expected to create fictional papers to go alongside 'real' research papers: the burden of additional work would be impractical. A possible antidote to this burden would be to utilize the design fiction trope that inspired the fictional paper approach; 'imaginary abstracts' [10]. As with fictional papers, imaginary abstracts pastiche and imitate their factual counterparts. Creating imaginary abstracts which hint at the implications of future adoption within the context of a research project, is a much more digestible proposition than creating a full fictional paper. However, as has been previously pointed out, with imaginary abstracts what is gained in accessibility is lost in potential depth when compared to fictional papers [48].

A raft of other design fictions feature compelling provocations which showcase ways in which researchers can move towards implications for adoption. A small selection of these are included here to provide the reader with a wider body of work to consider what implications for adoption may become. Uninvited Guests showcases one possible domestication of health monitoring devices, specifically focusing on the ways in which the user circumvents the devices' intended uses [76]. A Toaster for Life utilizes 3D modeling and product design techniques to unpack the nuances of a modular and connected toaster. In doing so Stead explores the broader implications for adoption vis-à-vis internet of things devices, suggesting uptake of these domestic connected devices may pivot around making elements of them recyclable, modular, and trackable [72]. Sans Duty explores a 'transparent tax zone', including a Tinder-style app which allows citizens to 'swipe right' to show how they would like to see their tax contributions spent. Among others, adoption implications that the project conveys include the exclusion of citizens without smartphones and an increase in selfishness resulting from the electronic 'participatory budgeting' system, such as the one depicted [26]. Edwards et al used a collaborative and iterative writing process to produce a series of design fictions which build from contemporary beekeeping practices and folklore, and in doing so exploring the implications of monetized-bee populations and micro-drone technologies [29]. In part what the diversity of approaches and domains shows us, is that there is no specific formular describing how to use design fiction to probe the significance of a technology's future adoption.
So far, in our discussion relating to implementing implications for adoption, we have advocated for design fiction as a well-suited approach. This is rooted in a natural alignment between the needs of implications for adoption, and some of the commonly-leveraged attributes of design fiction. In addition to that core argument it may be worth noting that while attention for design fiction in the context of HCI research has grown significantly in recent years, there is arguably a lack of consensus around the precise coordinates of what its role 'should' be. In aligning our characterization of implications for adoption with design fiction perhaps we concretize one possible use of design fiction and therefore contribute, in a small way, to disambiguating design fiction's role for HCI. However, implementing implications for adoption using design fiction is certainly not straightforward, an observation supported by those examples we have drawn upon. Although the examples show how design fiction touches upon the righthand side of our adapted hype cycle, and therefore the space which this paper's thesis aims to address, they conspicuously don't fit in to any kind of convention which we may appropriate as present as method for 'doing' implications for adoption. Unfortunately, a more profound inquiry into the details of how design fiction may be used to implement implications for adoption is beyond this paper's scope. In the following we will further unpack the practicalities of implementing implications for adoption, with a view to supporting and informing future research in this area.

\section{DISCUSSION}

We would like to repeat that, despite forwarding design fiction as a potential response to our call to incorporate implications for adoption into HCI research projects, our position is certainly not intended to be domineering or remissive with respect to other possible approaches. Put differently, the 'need' laid out in the first two sections of this paper stands independently from any possible solutions, and we commend any potentially workable responses to the argument. Each of the alternate approaches listed previously (including scenarios, research products, conceptual design proposals, critical design, etc) have merit and we encourage researchers to consider these as possible responses. With that said design fiction does appear to have attributes that are worthy and fitting with respect to what is needed to meaningfully consider implications for adoption. Refining and testing possible ways formats for incorporating implications for adoption into research projects is an area that would benefit from further inquiry.

As per our references to Liu et al [50] and Blackwell $[7,8]$ earlier, the HCI field is inherently interdisciplinary and diverse. The range of research conducted in the field that is published as part of CHI (as well as related conferences such as CSCW and DIS) is remarkably broad. With that breadth in mind it should come as no surprise although we posit that implications for adoption are a missing, but important part, of HCI research practice, that position is not 
a universal one encompassing the entire field. We not wish to suggest that all HCI research must consider some implications for adoption to be good research. To narrow down the categories of research we think implications for adoption could be particularly relevant to is a problem that would benefit from experimentation (from researchers working in varied areas) and additional investigation. However, despite being a question that deserves deeper discussion, as a starting point we suggest that any research that can be placed on the left of the hype cycle (i.e. that is or may become a 'technology trigger'), should arguably consider the implication of that research or technology's future adoption. As such research projects aligning to this category should be mindful of this paper's thesis.

The final question we wish to explore in this discussion is, what do implications for adoption 'look' like? For those scholars who are keen to embrace the argument in this paper, and are appreciative of our endorsement of design fiction; how should they proceed to implement implications for adoption in their next publication? Further, given their potential dangers, how could or indeed should, a 'genre convention' [cf. 25] around implications for adoption be established? In short, we feel that to develop nuanced answers to these questions, a practical exploration of the ideas we have presented is necessary. The argument we present is an ideological one, but comes packaged with the addition of some practical signposting towards design fiction as a suitable method. However, as with Odom et al's description of research products [56], our position is not intended to be reductive or prescriptive but hopes to open the concept for further development. In his critique of implications for design Kostakos writes "these are extremely polished pieces of text that do a wonderful job of not providing any reusable data, theory, or tools, yet manage to convince us that the implications are important" [41]. This sentiment is, perhaps, the most succinct explication of what researchers recognizing the importance of implications for adoption should aim to achieve.

\section{CONCLUSION}

This paper's aim is threefold. First, we reviewed a variety of literature describing different ways of considering what we refer to as technological adoption. In doing so we highlighted a space which researchers may leverage in order to contextualize the potential implications of the technologies they research when (or if) they eventually become adopted. Second, we referred to a range of HCIcentric literature in order to build an argument for why considering adoption in this way is not only relevant to our community, but is arguably essential in order to galvanize the field's substance as a driver of innovation. These introductory contributions lay the rhetorical foundation for implications for adoption. With the case established, the third and contribution the paper offers proposes design fiction as a fitting response to the need, and discusses the challenges and opportunities of implementing implications for adoption. In this paper we argue that by considering 'implications for adoption' HCI researchers may be better equipped to design, critique, and contribute to the proximate future which our community both creates, and thrives in.

\section{ACKNOWLEDGEMENTS}

This work was made possible by the RCUK Cyber Security for the Internet of Things Research Hub PETRAS (petrashub.org) under EPSRC grant EP/N02334X/1 and the RCUK Digital Economy Programme's Doctoral Training Centre HighWire (highwire.lancaster.ac.uk) under EPSRC grant EP/G037582/1. We would like to extend our gratitude and thanks to the anonymous reviewers who provided us with details, insightful, and fair feedback which helped us improve and craft this paper into its final form.

\section{REFERENCES}

1. Dennis A. Adams, R. Ryan Nelson, and Peter A. Todd. 1992. Perceived Usefulness, Ease of Use , and Usage of Information Technology: A Replication. MIS Quarterly 16, 2: 227-247. http://doi.org/10.2307/249577

2. Madeline Akrich. 1992. The De-scription of Technical Objects. In Shaping Technology/Building Society: Studies in Sociotechnical Change. The MIT Press, Cambridge, MA, 205-224.

3. Carla Alvial-Palavicino. 2016. The Future as Practice. A Framework to Understand Anticipation in Science and Technology. TECNOSCIENZA: Italian Journal of Science \& Technology Studies 6, 2: $135-172$.

4. James Auger. 2013. Speculative design: crafting the speculation. Digital Creativity 24, 1: 11-35.

5. Genevieve Bell and Paul Dourish. 2007. Yesterday's tomorrows: notes on ubiquitous computing's dominant vision. Personal and Ubiquitous Computing 11, 2: 133-143. http://doi.org/10.1007/s00779-006-0071-x

6. Izak Benbasat and Henri Barki. 2007. Quo vadis, TAM? Journal of the Association for Information Systems $\quad 8, \quad 4: \quad 211-218$ http://doi.org/10.1586/erd.10.82

7. Alan Blackwell. 2015. Filling the big hole in HCI research. Interactions 22, 6: 37-41. http://doi.org/10.1145/2830317

8. Alan F Blackwell. 2015. HCI as an Inter-Discipline. Extended Abstracts of the ACM CHI'15 Conference on Human Factors in Computing Systems 2: 503 516. http://doi.org/10.1145/2702613.2732505

9. Julian Bleecker. 2009. Design Fiction: A short essay on design, science, fact and fiction. Near Future Laboratory.

10. Mark Blythe. 2014. Research through design fiction. Proceedings of the 32nd annual ACM conference on Human factors in computing systems 
- CHI '14, ACM Press, 703-712. http://doi.org/10.1145/2556288.2557098

11. Mark Blythe and Enrique Encinas. 2016. The Coordinates of Design Fiction: Extrapolation, Irony, Ambiguity and Magic. Proc. GROUP'16: 345-354. http://doi.org/10.1145/2957276.2957299

12. Mark Blythe, Jamie Steane, Jenny Roe, and Caroline Oliver. 2015. Solutionism, the Game. Proceedings of the 33rd Annual ACM Conference on Human Factors in Computing Systems - CHI '15, ACM Press, 3849-3858. http://doi.org/10.1145/2702123.2702491

13. Mads Borup, Nick Brown, and Kornelia Konrad. 2006. The Sociology of Expectations in Science and Technology. Technology Analysis \& Strategic Management 18, September: 285-298.

14. Richard Buchanan. 1985. Declaration by Design: Rhetoric, Argument, and Demonstration in Design Practice. Design Issues, 2, 1: 4-22.

15. Laura Buttrick and Conor Linehan. 2014. Fifty Shades of CHI: The Perverse and Humiliating Human-Computer Relationship. 825-833. http://doi.org/10.1145/2559206.2578874

16. M. Callon, J. P. Courtial, and F. Laville. 1983. From translations to problematic networks: An introduction to co-word analysis. Social Science Information 22, 2: 191-235.

17. Parmit $\mathrm{K}$ Chilana, Andrew J Ko, and Jacob Wobbrock. 2015. From User-Centered to AdoptionCentered Design. Proceedings of the 33rd Annual ACM Conference on Human Factors in Computing Systems - CHI '15: 1749-1758. http://doi.org/10.1145/2702123.2702412

18. Paul Coulton, Dan Burnett, and Adrian Gradinar. 2016. Games as Speculative Design: Allowing Players to Consider Alternate Presents and Plausible Futures. Proceedings of the 50th Design Research Society Conference: 1-17.

19. Paul Coulton, Joseph Lindley, and Haider Ali. 2016. Design Fiction: Does the search for plausibility lead to deception? Proceedings of DRS 2016, Design Research Society 50th Anniversary Conference.

20. Aaron Crabtree, Alan Chamberlain, M Davies, et al. 2013. Doing Innovation in the Wild. Proceedings of the Biannual Conference of the Italian Chapter of SIGCHI: $1-9$. http://doi.org/10.1145/2499149.2499150

21. Andrew Crabtree, Tom Rodden, Peter Tolmie, and Graham Button. 2009. Ethnography considered harmful. Proceedings of the 27th international conference on Human factors in computing systems - CHI 09, October 2015: 879. http://doi.org/10.1145/1518701.1518835

22. Nicholas S. Dalton, Rebecca Moreau, and Ross K. Adams. 2016. Resistance is Fertile: Design Fictions in Dystopian Worlds. Proceedings of the 2016 CHI Conference Extended Abstracts on Human Factors in Computing Systems - CHI EA '16: 365-374. http://doi.org/10.1145/2851581.2892572

23. Fred Davis, Richard Bagozzi, and Paul Warshaw. 1989. User Acceptance of Computer Technology: A Comparison of Two Theoretical Models. Management Science 35, 8: 982-1003.

24. Andrew Dillon and Michael G Morris. 1996. User Acceptance of Information Technology:Theories and Models. Annual Review of Information Science and Technology.

25. Paul Dourish. 2006. Implications for design. Proceedings of the SIGCHI conference on Human Factors in computing systems - CHI '06: 541. http://doi.org/10.1145/1124772.1124855

26. James Duggan and Joseph Lindley. 2015. Sans Duty - Making Tax Visisble.

27. Anthony Dunne. 2006. Hertzian Tales: Electronic Products, Aesthetic Experience, and Critical Design. The MIT Press.

28. Anthony Dunne and Fiona Raby. 2013. Speculative Everything. The MIT Press, London.

29. Liz Edwards, Deborah Maxwell, Toby Pillatt, and Niamh Downing. 2016. Beebots-a-lula, Where's My Honey? Proceedings of the 9th Nordic Conference on Human-Computer Interaction NordiCHI '16, ACM Press, 1-10. http://doi.org/10.1145/2971485.2993924

30. Enrique Encinas and Mark Blythe. 2016. The Solution Printer: Magic Realist Design Fiction. CHI Extended Abstracts on Human Factors in Computing Systems, July 2015: 387-396.

31. M Fishbein and I Ajzen. 1975. ZEN, Belief, Attitude, Intention and Behavior: An Introduction to Theory and Research. Addison-Wesley, Reading, MA.

32. Foley, Jim. 1996. Technology Transfer from University to Industry. Communications of the ACM 39, 9. http://doi.org/10.1145/514236.514264

33. Bill Gaver and Heather Martin. 2000. Alternatives. Proceedings of the SIGCHI conference on Human factors in computing systems - CHI '00, ACM Press, 209-216. http://doi.org/10.1145/332040.332433

34. Saul Greenberg and Bill Buxton. 2008. Usability evaluation considered harmful (some of the time). Proceeding of the twenty-sixth annual CHI conference on Human factors in computing systems 
$\begin{array}{lcc}\text { - } & \text { CHI } & \text { '08: } \\ \text { http://doi.org/10.1145/1357054.1357074 }\end{array}$

111.

35. Felix Heibeck, Alexis Hope, and Julie Legault. 2014. Sensory Fiction: A Design Fiction of Emotional Computation. 35-40.

36. Ellen A Isaacs and John C Tang. 1996. Technology transfer: so much research, so few good products. Communications of the ACM 39, 9: 23-25. http://doi.org/10.1145/234215.234463

37. H. Järvenpää and S. J. Mäkinen. 2008. Empirically detecting the Hype Cycle with the life cycle indicators: An exploratory analysis of three technologies. 2008 IEEE International Conference on Industrial Engineering and Engineering Management, IEEM 2008: 12-16. http://doi.org/10.1109/IEEM.2008.4737823

38. D. Kirby. 2010. The Future is Now: Diegetic Prototypes and the Role of Popular Films in Generating Real-world Technological Development. Social Studies of Science 40, 1: 4170. http://doi.org/10.1177/0306312709338325

39. Ben Kirman, Conor Linehan, Shaun Lawson, and Dan O'Hara. 2013. CHI and the future robot enslavement of humankind: a retrospective. $\mathrm{CHI}$ '13 Extended Abstracts on Human Factors in Computing Systems on - CHI EA '13: 2199. http://doi.org/10.1145/2468356.2468740

40. Ronald Kline and Trevor Pinch. 1996. Users as Agents of Technological Change: The Social Construction of the Automobile in the Rural United States. Technology and Culture 37, 4: 763. http://doi.org/10.2307/3107097

41. Vassilis Kostakos. 2015. The big hole in HCI research. interactions 22, 2: 48-51. http://doi.org/10.1145/2729103

42. Shaun Lawson, Ben Kirman, Conor Linehan, et al. 2015. Problematising Upstream Technology through Speculative Design: The Case of Quantified Cats and Dogs. 2663-2672.

43. Shaun Lawson, Ben Kirman, and Conor Linehan. 2016. Power, participation, and the dog internet. interactions 23, 4: 37-41. http://doi.org/10.1145/2942442

44. Paul Legris, John Ingham, and Pierre Collerette. 2003. Why do people use information technology? A critical review of the technology acceptance model. Information \& Management 40, 3: 191-204. http://doi.org/10.1016/S0378-7206(01)00143-4

45. Harro Van Lente, Charlotte Spitters, and Alexander Peine. 2013. Comparing technological hype cycles: Towards a theory. Technological Forecasting and Social Change 80, 8: 1615-1628. http://doi.org/10.1016/j.techfore.2012.12.004
46. Chien-Hsin Lin, Hsin-Yu Shih, and Peter J. Sher. 2007. Integrating technology readiness into technology acceptance: The TRAM model. Psychology and Marketing 24, 7: 641-657. http://doi.org/10.1002/mar.20177

47. Joseph Lindley and Paul Coulton. 2015. Game of Drones. Proceedings of the second ACM SIGCHI annual symposium on Computer-human interaction in play.

48. Joseph Lindley and Paul Coulton. 2016. Pushing the Limits of Design Fiction. Proceedings of the 2016 CHI Conference on Human Factors in Computing Systems - CHI '16, ACM Press, 40324043. http://doi.org/10.1145/2858036.2858446

49. Conor Linehan, Ben J. Kirman, Stuart Reeves, et al. 2014. Alternate endings. Proceedings of the extended abstracts of the 32 nd annual ACM conference on Human factors in computing systems - CHI EA '14, ACM Press, 45-48. http://doi.org/10.1145/2559206.2560472

50. Yong Liu, Jorge Goncalves, Denzil Ferreira, Bei Xiao, Simo Hosio, and Vassilis Kostakos. 2014. CHI 1994-2013: mapping two decades of intellectual progress through co-word analysis. $\mathrm{CHI}$ '14 Proceedings of the SIGCHI Conference on Human Factors in Computing Systems, 3553-3562. http://doi.org/10.1145/2556288.2556969

51. Wendy E Mackay. 2000. Responding to cognitive overload: Co-adaptation between users and technology. Intellectica 30: 177-193.

52. Thomas Markussen and Eva Knutz. 2013. The poetics of design fiction. Proceedings of the 6th International Conference on Designing Pleasurable Products and Interfaces - DPPI'13: 231.

53. Eran May-Raz and Daniel Lazo. 2012. Sight. Retrieved October 27, 2014 from http://vimeo.com/46304267

54. Donald a. Norman. 2005. Human-centered design considered harmful. interactions 12, 4: 14. http://doi.org/10.1145/1070960.1070976

55. Donald A Norman and Roberto Verganti. 2014. Incremental and Radical Innovation: Design Research vs. Technology and Meaning Change. 30, 1. http://doi.org/10.1162/DESI

56. William Odom, Ron Wakkary, Youn-kyung Lim, Audrey Desjardins, Bart Hengeveld, and Richard Banks. 2016. From Research Prototype to Research Product. Proceedings of the 2016 CHI Conference on Human Factors in Computing Systems - CHI '16: 2549-2561. http://doi.org/10.1145/2858036.2858447

57. Nelly Oudshoorn and Trevor Pinch. 2003. How Users Matter: The Co-Construction of Users and 
Technology. The MIT Press, Cambridge, MA.

58. Garry D Peterson, Graeme S Cumming, and Stephen R Carpenter. 2003. Scenario Planning: a Tool for Conservation in an Uncertain World. Essay 358 Conservation Biology Conservation Biology 17, 2: 358-366. http://doi.org/10.1046/j.1523-1739.2003.01491.x

59. James Pierce and Eric Paulos. 2015. Making Multiple Uses of the Obscura 1C Digital Camera: Reflecting on the Design, Production, Packaging and Distribution of a Counterfunctional Device. Proceedings of the 33rd Annual ACM Conference on Human Factors in Computing Systems: 21032112. http://doi.org/10.1145/2702123.2702405

60. Trevor J Pinch and Wiebe E Bijker. 1984. The Social Construction of Facts and Artefacts: or How the Sociology of Science and the Sociology of Technology might Benefit Each Other. Social Studies of Science 14, 3: 399-441. http://doi.org/10.1177/030631284014003004

61. Trevor J Pinch and Wiebe E Bijker. 1984. The Social Construction of Facts and Artefacts: or How the Sociology of Science and the Sociology of Technology might Benefit Each Other. Social Studies of Science 14, 3: 399-441. http://doi.org/10.1177/030631284014003004

62. Stuart Reeves. 2015. Locating the "Big Hole" in Hci. August: 1-8.

63. Stuart Reeves. 2015. Human-computer interaction as science. 5th Annunal Aarhus Conference on Critical Alternatives. http://doi.org/10.7146/aahcc.v1i1.21296

64. Ahti Salo and Kerstin Cuhls. 2003. Technology foresight - Past and Future. Journal of Forecasting 22, 2-3: 79-82. http://doi.org/10.1002/for.846

65. Ahti Salo, Tommi Gustafsson, and Ramakrishnan Ramanathan. 2003. Multicriteria Methods for Techonology Foresight. Journal of Forecasting 22: 235-255. http://doi.org/10.1002/for.850

66. Corina Sas, Steve Whittaker, Steven Dow, Jodi Forlizzi, and John Zimmerman. 2014. Generating implications for design through design research. Proceedings of the 32nd annual ACM conference on Human factors in computing systems - CHI '14, ACM Press, 1971-1980. http://doi.org/10.1145/2556288.2557357

67. Paul J H Schoemaker. 1995. Scenario Planning: A tool for Strategic Thinking. Sloan Management Review 36, 2: 25-40.

68. Albert H Segars and Varun Grover. 1993. Reexamining perceived ease of use and usefulness. MIS Quarterly 17, 4: 517-525.

69. Phoebe Sengers, Kirsten Boehner, Shay David, and
Joseph "Jofish" Kaye. 2005. Reflective Design. Proceedings of the 4th decennial conference on Critical computing: between sense and sensibility: 49-58. http://doi.org/10.1145/1094562.1094569

70. Roger Silverstone. 2006. Domesticating domestication. Reflecting on the life of a concept. In Domestication Of Media And Technology, Thomas Berker, Maren Hartmann, Yves Punie and Katie Ward (eds.). Open University Press, 229-247.

71. Marie Louise Juul Søndergaard and Lone Koefoed Hansen. 2016. PeriodShare. Proceedings of the 9th Nordic Conference on Human-Computer Interaction - NordiCHI '16, ACM Press, 1-6. http://doi.org/10.1145/2971485.2996748

72. Michael Stead. 2016. A Toaster For Life: Using Design Fiction To Facilitate Discussion On The Creation Of A Sustainable Internet of Things. Proceedings of DRS 2016, Design Research Society 50th Anniversary Conference: 1-20.

73. Bruce Sterling. 2005. Shaping Things. The MIT Press.

74. Miriam Sturdee, Paul Coulton, Joseph G. Lindley, Mike Stead, Haider Ali, and Andy Hudson-Smith. 2016. Research Fiction: How to Build a Voight Kampff Machine. Proceedings of the $2016 \mathrm{CHI}$ Conference Extended Abstracts on Human Factors in Computing Systems - CHI EA '16, ACM Press, 375-386. http://doi.org/10.1145/2851581.2892574

75. Lucy Suchman. 1987. Plans and situated actions: the problem of human-machine communication. Cambridge University Press.

76. Superflux. Uninvited Guests. Retrieved September 17, 2015 from http://www.superflux.in/work/uninvited-guests

77. Stuart Walker. 2013. Imagination's Promise: Practice-Based Design, Research for Sustainability. In The Handbook for Design Sustainability, Stuart Walker and Jacques Giard (eds.). Bloomsbury, London \& New York, 460-461.

78. Mark Weiser. 1999. The computer for the $21 \mathrm{st}$ century. ACM SIGMOBILE Mobile Computing and Communications Review 3, 3: 3-11. http://doi.org/10.1145/329124.329126

79. Richmond Y Wong and Deirdre K Mulligan. 2016. When a Product Is Still Fictional : Anticipating and Speculating Futures through Concept Videos. 121133.

80. S Woolgar. 1991. Configuring the user: The case of usability trials. In A Sociology of Monsters, John Law (ed.). Routledge.

81. Richard M. Young and Phil Barnard. 1987. The use of scenarios in human-computer interaction research. ACM SIGCHI Bulletin 18, 4: 291-296. 
http://doi.org/10.1145/1165387.275645 